\title{
The effect of person-organization fit and workplace fun on intention to stay with work engagement as a mediating variable
}

\author{
S. Apriyanti \& E.S. Pusparini \\ Faculty of Economics and Business, Universitas Indonesia, Jakarta, Indonesia
}

\begin{abstract}
The purpose of this research is to examine the effect of person-organization fit and workplace fun on work engagement and intention to stay and to examine work engagement as a mediating variable between the effects of person-organization fit and workplace fun on intention to stay. This research is a quantitative study with a cross-sectional design. An online questionnaire was used to collect data. In total, 342 employees from one of the leading companies in the retail industry in Indonesia participated in this research. The data analyzed by using SEM show that person-organization fit and workplace fun has a significant effect on work engagement, but there is no significant effect of workplace fun on intention to stay. Furthermore, the results of this research underscore the role of work engagement, which acts as a mediator between the effects of person-organization fit and workplace fun on intention to stay.
\end{abstract}

\section{INTRODUCTION}

The topic of employee turnover is still considered as an interesting topic for researchers and practitioners for several years (Hom, Shaw, Lee, \& Hausknecht, 2017). Robbins and Judge (2017) stated that a high turnover rate can disrupt the efficiency of the organization. Furthermore, Ghosh, Satyawadi, Joshi, and Shadman (2012) stated that an employee leaving an organization is psychologically painful for the organization and also other employees because it does not only cause setbacks in the professional field but also disrupt the social life in the organization. On the other hand, Ghosh, Satyawadi, Joshi, and Shadman (2012) stated that today, organizations have realized that it is important to retain employees and build a stable workforce and then focus on the formulation and enforcement of a strong retention strategy to effectively lessen turnover. On the contrary to turnover intention, intention to stay refers to the willingness of an individual who consciously and deliberately wants to stay with the organization (Tett \& Meyer, 1993). In simple terms, Kim, Price, Mueller, and Watson (1996) stated that intention to stay is the opposite of turnover intention.

\section{LITERATURE REVIEW}

Robbins and Judge (2017) stated that person-organization fit is a theory that explains an individual's interest in working in an organization and the individual is chosen by the organization to work because the values of the individual match with the organizational values, so the individual will leave the organization when he feels there is no match between them. One of the factors that causes high engagement is the conformity between individual values and organizational values. In line with this, Memon et al. (2018) in their research found that person-organization fit is a strong predictor of work engagement.

Person-organization fit is considered important because it is associated with a more positive work attitude, lower task performance, turnover intention, and suppressed stress of organizational behavior (Kinicki \& Fugate, 2016). Bakker and Leiter (2010) defined that work engagement is a satisfied and positive state of mind linked to work characterized by dedication, vigor, and 
absorption. A research conducted by Rai, Ghosh, and Dutta (2019) found that engagement has a positive influence on intention to stay where the level of engagement assessed or perceived by individuals with their work tends to determine intention to stay.

Memon et al. (2018) stated that when individuals assess the conformity of the values they have with the values of the organization, these individuals will also feel that the organization is able to meet their needs well, and having the same attributes as other employees will cause individuals to be highly engaged. One of the main reasons that are keeping employees connected to the organization is the high engagement and emotional affection. Becker (2012) stated that a fun work environment has been used as a way to build an organizational culture that can support increased work engagement, employee performance, and employee retention. In addition, Fluegge (2008) defined workplace fun as interpersonal, social, or any task that is fun or humorous that can provide entertainment, pleasure, and a feeling of enjoyment to individuals. Consequently, workplace fun will effectively reduce turnover intention if the individuals feel engaged with the company.

\section{RESEARCH METHODOLOGY}

This research used a quantitative method with a convenience sampling technique and was conducted by distributing online questionnaires to the employees of one of the leading companies in the retail industry in Indonesia. The number of respondents was 342. We adopted items from the report by Jung and Yoon (2013) to measure person-organization fit, scale developed by Tews, Michel, and Allen (2014) to measure workplace fun, and UWES-9 developed by Schaufeli et al. (2006) to measure work engagement and items from Jung and Yoon (2013) to measure intention to stay. In this study, the researchers decided to continue using the scale developed by Jung and Yoon (2013) by changing negative statements to positive ones without changing the existing meaning. In line with that, Gupta and Singh (2018) also measured the intention to stay variable through a reversal of the turnover intention scale developed by Mobley et al. (1979) by changing negative statements to positive ones without changing the meaning. All measures used a 7-point Likert scale. The data were analyzed using structural equation modeling with LISREL to test the proposed model (Figure 1).

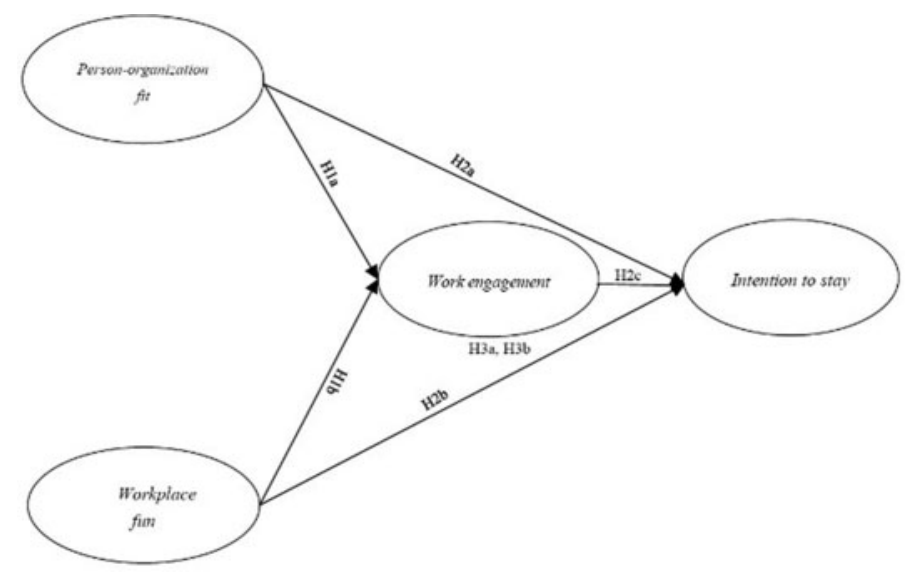

Figure 1. Research model

\section{RESULTS}

The questionnaires were filled by 281 women $(82.16 \%)$ and 61 men $(17.84 \%)$. The majority of respondents belonged to the $20-29$ years age group (65.27\%). Almost $81 \%$ of the respondents 
worked in PT X for 1-10 years. In this study, there are also ten values categorized in the good fit category: GFI (0.90), RMSEA (0.073), RMR (0.044), ECVI, TLI (0.97), NFI (0.97), RFI (0.96), IFI, (0.98), CFI (0.98), and CAIC. Hair et al. (2014) stated that using three to four fit indices provides evidence of adequate model fit. Therefore, the proposed research model can be declared to have met the good fit criterion. After the research model met the criterion of goodness of fit, the process was continued with a test of direct effect between variables. This study applied a one-tailed hypothesis test; therefore hypotheses will be accepted if the t-value is $\geq 1.645$ (Lind, Marchal, \& Wathen, 2017). In addition, it tested the mediating role of work engagement between personorganization fit and workplace fun to intention to stay. The findings of this research can be seen as shown below.

Table 1. Results of hypothesis testing.

\begin{tabular}{llll}
\hline Hypotheses & SLF & t-values & Decision \\
\hline$H 1 a:$ POF WE & 0.52 & 8.21 & Supported \\
$H 1 b:$ WF-WE & 0.34 & 5.51 & Supported \\
\hline Hypotheses & SLF & t-values & Decision \\
\hline$H 2 a:$ POF-ITS & 0.45 & 4.77 & Supported \\
$H 2 b:$ WF-ITS & 0.06 & 0.71 & Not Supported \\
$H 2 c:$ WE-ITS & 0.24 & 2.82 & Supported \\
$H 3 a:$ POF-WE-ITS & & 2.695 & Supported \\
$H 3 b:$ WF-WE-ITS & & 2.533 & Supported \\
\hline
\end{tabular}

\section{DISCUSSION AND CONCLUSION}

Based on Table 1, person-organization fit has a significant and positive effect on work engagement. In line with that, a research conducted by Memon et al. (2018) also found that person-organization fit is a strong predictor of work engagement in professional workers in the oil and gas industry. In addition, the relationship between workplace fun and work engagement is also significant and positive. This result is in line with the research conducted by Fluegge-Woolf (2014), who found that when workplace fun increases, there is also an increase in work engagement.

Person-organization fit has a direct and significant positive effect on intention to stay. In line with that, Demir, Demir, and Nield (2014) said that the higher the individual's assessment of person-organization fit, the higher the individual's desire to stay in the organization. However, the $\mathrm{t}$-value on the relationship between the workplace fun on intention to stay in this study is $<1.645$, which is equal to 0.71 , so it can be stated that it has no significant effect. Further, the result of this research proves that work engagement has a direct and significant positive effect on intention to stay. Kim and Yoo (2018) also found that work engagement has an effect on intention to stay.

The significance of the role of work engagement as a mediating variable was tested using the Sobel Test. Based on that, it can be concluded that work engagement has a good role as a mediator, which proves that the influence of person-organization fit maximizes the intention to stay if employees have a good level of engagement. In addition, the role of work engagement in mediating the influence of workplace fun on intention to stay shows that with work engagement, it can further increase the influence of workplace fun and the intention to stay. Sakr, Zotti, and Khaddage-Soboh (2019) stated that workplace fun has proven to be a key element in reducing work stress, absenteeism, and turnover as well as maintaining great customer service, employee retention, and attracting talent. However, everything is related to one essential concept, namely, engagement. Becker (2012) also stated that a fun work environment has been used as a way to build an organizational culture that can support increased work engagement, employee performance, and 
employee retention. Tsaur, Hsu, and Lin (2019) stated that if the organization can build and develop a fun workplace, it will help employees boost their social relationship and give social support to overcome sources of pressure, thus enabling employees to be more dedicated to their jobs.

In conclusion, this study reveals that the effect of person-organization fit and workplace fun on intention to stay is mediated by work engagement. This shows that work engagement is a very important factor in increasing intention to stay in order to increase employee work engagement. Therefore, the company should increase workplace fun and person-organization fit.

\section{REFERENCES}

Becker, F.W. (2012), The Impact of Fun in The Workplace on Experienced Fun, Work

Engagement, Constituent Attachment, and Turnover Among Entry-Level Service Employees, Disertation, Pennsylvania State University.

Demir, M., Demir, S. S., \& Nield, K. (2014), “The relationship between person-organization fit, organizational identification and work outcomes", Journal of Business Economics and Management", Vol. 16 No. 2, pp. 369-386.

Fluegge-Woolf, E.R. (2014), "Play hard, work hard: fun at work and job performance", Management Research Review, Vol. 37 No. 8, pp. 682-705.

Ghosh, P., Satyawadi, R., Joshi, J. P. \& Shadman, M. (2012), "Who stays with you? factors predicting employees' intention to stay", International Journal of Organizational Analysis, Vol. 21 No. 3, pp. 288-312.

Gupta, A. \& Singh, V. (2018), "Enhancing intention to stay among software professionals", Academia Revista Latinoamericana de Administracion, Vol. 31 No. 3, pp. 569-584.

Hair, J.F., Black, W.C., Babin, B.J., \& Anderson, R.E. (2014). Multivariate Data Analysis $7^{\text {th }}$ Edition. Pearson New International Edition: London.

Hom, P.W., Shaw, J.D., Lee, T.W., \& Hausknecht, J.P. (2017), “One hundred years of employee turnover theory and research", Journal of Applied Psychology,Vol. 102 No. 3,pp. 530-545.

Jung, H.Y \& Yoon, H.H. (2013), "The effects of organizational service orientation on person - organization fit and turnover intent", The Service Industries Journal, Vol. 33 No. 1, pp. 7-29.

Kim, S.W., Price, J. L., Mueller, C. W., \& Watson, T. W. (1996). The determinants of career intent among physicians at a U.S. Air Force Hospital. Human Relations, 49(7), 947-976.

Kim, K. J., \& Yoo, M. S. (2018). The Influence of Psychological Capital and Work Engagement on Intention to Remain of New Graduate Nurses. JONA: The Journal of Nursing Administration, 48(9), 459-465.

Kinicki, A. \& Fugate, M. (2016), Organizational Behavior: A Practical, Problem-Solving Approach, New York: McGraw-Hill

Lind, D.A., Marchal, W.G., \& Wathen., (2017). Statistical Techniques in Business \& Economics 17th Edition. McGrawHill: New York.

Memon, M.A., Salleh, R., Nordin, S.M., Cheah, J.H., Ting, H. \& Chuah, F. (2018), "Personorganisation fit and turnover intention: the mediating role of work engagement", Journal of Management Development, Vol. 37 No. 3, pp. 285-298.

Rai, A.and Ghosh, P. \& Dutta, T. (2019), “Total rewards to enhancee employees'intention to stay: does perception of justice play any role?", Evidence-based HRM, Vol. 7 No. 3, pp. 262-280.

Robbins, S.P \& Judge, T. A. (2017), Organizational Behaviour Seventeenth Edition, London: Pearson Education.

Sakr, C., Zotti, R., \& Khaddage-Soboh, N. (2019). The impact of implementing fun activities on employee's engagement: The case of Lebanese financial institutions, International Journal of Organizational Analysis, 27 (5), 1317-1335.

Schaufeli, W.B., Bakker, A.B., \& Salanova, M. (2006), "The measurement of work engagement with a short questionnaire a cross-national study", Educational and Psychological Measurement, Vol. 66 No. 4, pp. 701-716.

Tett, R.P. \& Meyer, J.P. (1993), “Job satisfaction, organizational commitment, turnover intention, and turnover: path analyses based on meta-analytic findings", Personnel Psychology, Vol. 46, pp. 259-293.

Tews, M.J., Michel, J.W., \& Allen, D.G. (2014), "Does fun pay? the impact of workplace fun on employee turnover and performance", Cornell Hospitality Quarterly, Vol. 54 No. 4, pp. 370-382.

Tsaur, S.H., Hsu, F.S., \& Lin, H. (2019), "Workplace fun and work engagement in tourism and hospitality: the role of psychological capital", International Journal of Hospitality Management, Vol. 81 No. 2019, pp. $131-140$. 